\title{
Analysis on the Problems and Countermeasures of the Management of University Sports Venues
}

\author{
Juhai Wang \\ Institute of Physical Culture, Weinan Normal University, Weinan, Shaanxi, 714099
}

Keywords: University; Sports Hall; Problem Analysis

\begin{abstract}
With the continuous improvement of material living standards, people's health awareness has also been continuously enhanced. The concept of lifelong sports has gradually penetrated the hearts of the people, and the demand for exercise has become higher and higher. Sports venues are the main place for people to carry out sports activities, but at this stage, China's public sports venues are very rare, directly affecting the development of mass sports. In response to this situation, the State Sports General Administration issued an order to open colleges and universities to provide more venues for sports activities, expand the scope of sports activities, and solve the shortage of physical exercise venues. However, after the opening of college sports venues, it has undoubtedly increased the difficulty of management. The paper analyzes the problems existing in the management of college sports venues and proposes specific solutions.
\end{abstract}

\section{The Functional Characteristics of College Sports Venues}

Sports venues are more important than public sports venues, and the functions of college sports venues are mainly reflected in the following aspects:

Teaching needs and physical exercise are the basic functions of college sports venues. Students exercise in the stadiums and enjoy the facilities of the stadiums in order to improve the overall quality of students. The stadiums must meet the daily physical education needs and meet the special requirements of the training of the sports teams in the school. In addition, various sports competitions and activities of the colleges and universities, and the after-school sports activities organized by the students are also carried out in the stadiums. The venue is an infrastructure that caters to all types of professional, amateur sports or events. Second, the social needs of sports activities. The development of college sports activities towards socialization is an inevitable trend. Therefore, the functions of sports venues are not limited to physical education and daily sports activities within the school, but also provide venues for relevant social sports activities, such as enterprises and institutions, and college sports. The opening of the venue is also very beneficial for students to integrate into society. Finally, provide venues for major sporting events. At present, many cities in China do not have comprehensive sports venues. Therefore, college sports venues must take up the functions of providing venues for large-scale sports events. This will not only reduce the funds for building stadiums in cities, but also reduce the cost of maintaining stadiums in colleges and universities. Society and colleges can achieve a win-win situation.

\section{The Operating Characteristics of College Sports Venues}

Compared with public sports venues, the operation of college sports venues reflects the following characteristics: First, there are restrictions on opening hours. The opening of college sports venues cannot affect the normal teaching of schools. Therefore, the opening hours of college sports venues are different from the opening hours of public sports venues. If the opening of sports venues will affect the normal teaching of schools or affect the physical activities of schools, It will take the lead. The so-called spillover of income means that the economic activities of individuals or groups bring beneficial effects to others and society. The biggest benefit of the opening of college sports venues is to improve the overall quality of the people; physical exercise can not only enhance the physical fitness of the people, but also improve in this sense, the opening of college sports 
venues can indirectly increase the productivity of society. Again, it is exclusive. Although the opening of college sports venues has improved the convenience of social exercise for the public, it is a limited resource. The occupation of the society will inevitably affect the normal use of college teaching. Therefore, the operation and management of college sports venues have a certain degree of personalization. Finally, it has a certain public welfare. Sports venues are an important educational resource for colleges and universities, and relevant national laws clarify the public welfare of higher education. Therefore, stadiums and stadiums must also be managed and operated in a public welfare manner.

\section{The Problems in the Management of College Sports Venues}

Although the stadium has important functions, the opening of college sports venues has also added certain difficulties to its management. Specifically, the management of colleges and universities in China currently has the following problems:

As a professional sports venue, the management of sports venues requires professional personnel to manage, maintain and operate. However, at present, the talents of sports stadium management in China's colleges and universities are very rare. According to the relevant investigation report, the managers of non-professional backgrounds in the management of sports stadiums in colleges and universities occupy more than $80 \%$ of all personnel. Whether it is the management and maintenance of sports facilities or daily operation management, there is a lack of scientific management theory. And management personnel, whether serving on-campus or off-campus, lack basic service attitudes and directly affect the experience of the venue users. The main reason for the serious shortage of management talents in colleges and universities is that college administrators pay insufficient attention to the management of sports venues. For these talents, there is a lack of vocational training, and the introduction of talents does not fully consider the comprehensive conditions of their titles and academic qualifications. Low cost leads to management personnel lacking professional knowledge and skills, and lacks the necessary incentive mechanism, which directly affects the management and operation effect of sports venues.

The most prominent thing about the opening of college sports venues is the safety issue, including the personal safety of teachers and students on campus and the accidental injuries that may occur during the exercise of external fitness personnel. When the off-campus personnel enter the stadium for physical exercise, the overall quality of the school is quite different. Some people with poor overall quality may damage the sports facilities in the school. In addition, campus violence may occur, which directly affects the teachers and students of the school. In addition, accidental injuries caused by off-campus personnel during physical exercise in the stadiums in the school are also likely to cause legal disputes. Some colleges lack a comprehensive set of accident response measures. Often, it is impossible to clarify the liability of the accident and lead to legal disputes.

Although many college sports venues have established relevant management systems, the rules and regulations are too old and not updated in time according to the development of sports venues; and the management systems of some colleges and gymnasiums are mostly in the form, lacking operability in the specific implementation process. Even if the rules and regulations are hung in the conspicuous position of the venue, these rules and regulations are often lack of binding for off-campus personnel. Some exercisers wear slippers, shoes, high-heeled shoes, etc., and even some poor quality people smoke, throw garbage, and destroy in the venue. The sports facilities in the venue affect the management order of the stadiums. In addition, the unscientific marketing methods of sports venues will also have an important impact on their normal management and sustainable development. Although college sports venues have certain public welfare, rich and efficient marketing methods are necessary measures to expand the influence of venues and bring more economic benefits. At present, the marketing of college sports venues mostly uses print advertisements for publicity. This kind of publicity strategy has a narrow impact on the area and only affects the residents around the school. In addition, although some venues use online media for publicity, the amount of information published is very limited. Not yet rid of the influence of 
traditional means.

\section{Strategies for Improving the Management of College Sports Venues}

In view of the problems existing in the management of college sports venues in China, we can improve from the following aspects:

The rules and regulations are the scientific code of conduct for a certain management object, and require the management object to cooperate in accordance with the established rules and regulations. It can be seen that the rules and regulations have certain constraints on the management object, and the daily behavior of the management object is specification. University administrators should formulate a complete and operable management system for sports venues, update old content in time, establish a complete venue management system based on their actual situation, improve the social value of the venue, and explore a set of A management method that is consistent with the actual situation of the school and follows the laws of the market and the laws of sports. In addition, it is necessary to strengthen the propaganda of college sports venues and use rich marketing methods to expand the influence of sports venues. You can use the radiation influence of the residents around the university to guide them to rational consumption; give full play to the role of Internet marketing, and publicize through new and old media such as smartphone clients, the Internet, newspapers, and television to improve the social influence of the stadium; It can also print a fitness instruction brochure to investigate the consumption goals and consumption abilities of the consumer groups, and to target targeted sports services for people with different needs.

The stadiums and gymnasiums in the university have a large flow of people, complex personnel structure, and unlimited access. Although some venues have monitoring equipment installed, but there are fewer laying points, coupled with high maintenance costs, the monitoring system is ineffective, so college sports venues often occur. For such security problems, you can post safety signs, alarm calls, etc. in the stadium to play a vigilant role; valuables should be placed in the administrator, or configure the password cabinet; in the stadium opening hours, areas and other aspects and normal The teaching activities are divided to avoid the influence of outsiders on the normal teaching order of the school; increase the security force during the peak of physical exercise; increase the number of monitoring equipment, especially some dead corners, to expand the scope of monitoring and ensure environmental safety. In addition, for the frequent occurrence of sports injuries, the school should give high priority to provide a safe and comfortable fitness environment for physical exercise personnel; establish a comprehensive and meticulous sports injury accident emergency plan, and cooperate with insurance companies to purchase sports injuries.

First, optimize the age structure of the stadium management staff, inject fresh blood into the stadium management team, selectively recruit professional talents, and teach more management experience to middle-aged managers with long working years. Realize the transition between new and old managers. Secondly, improve the professional ability of managers, provide more opportunities for sports venue managers to receive vocational training, and go to universities with higher stadiums to visit and learn, and learn more advanced management concepts; organize experts to go deep into the campus. Professional lectures on stadium management enriched its management theory knowledge; special training for managers, such as management and maintenance of sports equipment, safety management of venues; strengthening the academic education of managers and improving their academic qualifications. Finally, the scientific performance appraisal system is implemented for the stadium management team, and the management personnel's professional attitude, responsibility, work enthusiasm, work effect, etc. are refined, and the appraisal results are linked with their salary levels to stimulate their work enthusiasm. Improve management.

\section{Conclusion}

In short, the opening of college sports venues not only improves the utilization of social resources, but also facilitates the physical exercise of the people. Of course, the current management of college sports venues is extensive, so there are still lack of talents, many security 
problems, lack of management systems and scientific business strategies. In the daily management, we should improve the above problems, strengthen the training of talents, provide more opportunities for the stadium management personnel to receive vocational training, take measures to improve the safety of the school, and formulate a scientific management system and a scientific management strategy. In addition, college leaders should also pay more attention to the management of sports venues, in order to improve the efficiency of the management of college sports venues, fully play the functions of sports venues, and promote the smooth implementation of comprehensive health plans.

\section{Acknowledgements}

Fund Project: This work was financially supported by Basic Research Projects of Weinan Technology Bureau (2017JCYJ-2-5), Education Science International Cooperation Research Projects of Weinan Normal University (17GJHZ15) and Shaanxi Social Science 2018 Projects of Major Theoretical and Practical Problems Research (2018Z001).

\section{References}

[1] Shi Jianguo. Related Factors of Stadium Management in Colleges and Universities [J]. Journal of Mudanjiang Teachers College: Natural Science Edition, 2015(3): 193.

[2] Shi Canbin, Ge Chao. A Preliminary Study on the Industrialization Management of Stadiums and Gymnasiums in Colleges and Universities [J].Journal of Huizhou University: Social Science Edition, 2015(4):36-37.

[3] Zhu Yaqin, Zhu Zhiping. Application of Customer Relationship Management Concept in the Management of University Sports Venues [J]. Journal of Beijing Sport University, 2014(10): 180-181.

[4] Liu Guanyuan, Guo Li. Reform of the construction of stadiums, facilities and equipment in colleges and universities [J]. Journal of Shandong Institute of Physical Education, 2014(1): 61-63.

[5] Liu Guanyuan. The Characteristics of Chinese Sports in the 21st Century and the Development Countermeasures of Physical Education Colleges and Departments in Colleges and Universities [J]. Journal of Sports Adult Education, 2013(2):110-112.

[6] Wang Zhen, Li Yanzhen. The Dilemma and Optimization Strategy of University Sports Venues Opening to the Society in China [J]. Journal of Beijing Sport University, 2018(1): 91-96

[7] Zhang Jian, Zhang Jianhua, Wang Lin. Current Situation and Countermeasures of Sports Management in Colleges and Universities [J]. Journal of Hebei Institute of Physical Education, 2013(5): 21-24. 